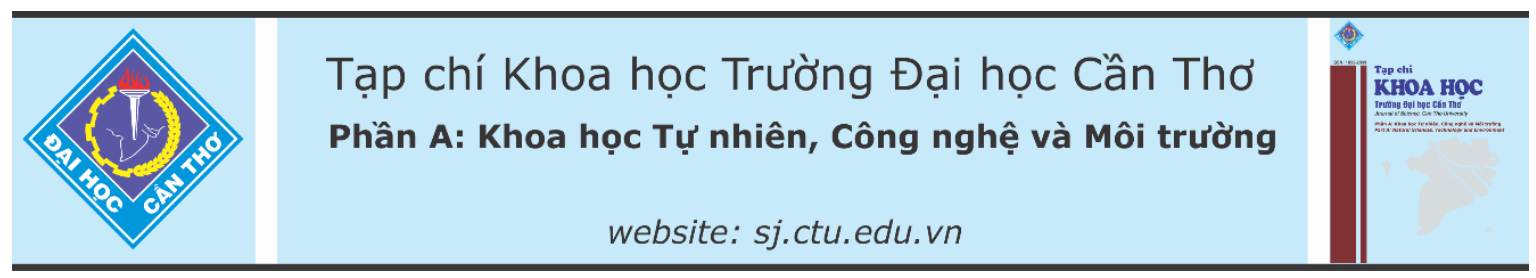

DOI:10.22144/ctu.jvn.2021.087

\title{
SỰ ĐA DẠNG CỦA BỌ ĐUÔI BẬT (COLLEMBOLA) Ở VƯờn QUỐC GIA BA Vİ
}

\author{
Nguyễn Thị Thu Anh*, Phùng Thị Hồng Lưỡng và Nguyễn Đức Anh
}

Phòng Sinh thái môi truờng đất, Viện Sinh thái và Tài nguyên Sinh vật, Viện Hàn lâm Khoa học và Công nghệ Việt Nam

*Nguoòi chịu trách nhiệm về bài viết: Nguyễn Thị Thu Anh (email: nthuanh189@gmail.com)

\section{Thông tin chung:}

Ngày nhận bài: 26/01/2021

Ngày nhận bài sưa: 22/04/2021

Ngày duyệt đăng: 25/06/2021

Title:

Diversity of springtail species (Collembola) in Bavi National Park

\section{Tù khóa:}

Bo nhảy, Collembola, đa dạn, nhân tác, thảm thục vật

\section{Keywords:}

Anthropogenic, Collembola, diversity, springtail, vegetation

\begin{abstract}
The species composition and distribution of the springtails (Collembola) were studied based on samples collected from three types of habitats: natural forest, plantation and brushes-shrubs. The samples were taken by Gorny and Grum' method (1993) in two seasons with the use of a specialized split core. The materials were subsequently extracted in a Berlese Tullgren's apparatus for 7 days. Collembolan communities were rather diverse in families, genera, species. In the three habitats studied where samples collected, natural forest was the most diverse one and were marked for a considerable contribution of forest species such as Lepidonella annucornis, Callyntrura sp.2, Dicranocentroides clitellatus, Arrhopalites sp. 1 , Ptenothrix sp.. . The characteristic species from artificial forest is Pseudachorutes dubius. Collembola represented in the shrub land are Sminthurus $s p .1$ and Neosminthurus sp.I. The distribution pattern, life forms and diversity of Collembola communities in the soils of Ba Vi National Park were influenced by the environmental conditions. Soil collembolans can be a good indicator of the type and degree or soil transformation in Ba Vi National Park.
\end{abstract}

\section{TÓM TẮT}

Nghiên cứu đa dạng thành phần loài và phân bố của bo đuôi bật (Collembola) được thực hiện trên 3 kiểu sinh cảnh đại diện của hệ sinh thái rùng thuộc Vườn Quốc gia Ba Vì: rùng tư nhiên, rùng trồng, trảng cỏ cây buii. Mẫu vật được thu bằng dụng cu chuyên dụng theo 2 mùa trong năm bằng phioong pháp thu mẫu được mô tả bởi Gorny \& Grum (1993). Các mẫu vật được tách ra khỏi đất bằng phễu Berlese Tullgren trong thời gian 7 ngày. Quần xã Collembola ở vuờn quốc gia Ba Vi khá đa dạng về thành phần họ, giống, loài. Trong 3 sinh cảnh nghiên cưu, rù̀ng tự nhiên là sinh cảnh đa dạng nhất, được đặc trung bởi sư có mặt của các loài có nguồn gốc tù rùng, đó là Lepidonella annucornis, Callyntrura sp.2, Dicranocentroides clitellatus, Arrhopalites sp. ${ }_{1}$, Ptenothrix sp. . Loài đặc trung cho sinh cảnh rùng trồng là Pseudachorutes dubius; đặc trưng cho trảng cỏ là Sminthurus sp. ., Neosminthurus sp. .. Đa dạng các nhóm phân loại, nhóm dạng sống của Collembola thay đổi khác nhau phu thuộc vào điều kiện sinh thái cu thể của sinh cảnh. Quần xã bo đuôi bật (Collembola) có thể được xem nhu nhóm sinh vật chi thị cho loại hình thảm thực vật và mức độ tác động nhân tác đến môi trường đẩt.

\section{GIỚI THIÊUU}

Trong quần xã động vật đất, động vật chân khớp bé (Microarthropoda) phải kể đến bọ đuôi bật
(Collembola) với kích thước cơ thể từ $0,1-0,2$ đến 2$3 \mathrm{~mm}$, là nhóm chiếm ưu thế, tham gia tích cực vào các quá trình tạo đất, quyết định nhiều hoạt tính sinh 
học quan trọng của môi trường và góp phần nâng cao độ phì nhiêu của đất. Chúng là thành phần quan trọng tạo nên tính đa dạng của thế giới động vật đất. Cấu trúc quần xã bọ đuôi bật (Collembola) ở đất bao gồm đa dạng thành phần loài, độ phong phú, đặc điểm phân bố,... có liên quan chặt chẽ đến điều kiện khí hậu và môi trường, với loại đất, kiểu thảm phủ thực vật và loại cây trồng hay chế độ canh tác đất và phân bón (Nguyễn Trí Tiến, 1995). Cấu trúc này được xem như một chỉ thị sinh học, chỉ thị các biến đổi tự nhiên và nhân tác của môi trường đất (Stach, 1965; Nguyễn Trí Tiến, 1995; Nguyễn Trí Tiến và ctv., 2007; Nguyễn Trí Tiến và ctv., 2008; Nguyễn Thị Thu Anh \& Nguyễn Trí Tiến, 2005a, 2005b; Nguyễn Thị Thu Anh và ctv., 2013). Vườn quốc gia (VQG) Ba Vì (Hà Nội) có hệ động thực vật phong phú và đa dạng, mang những đặc trưng của rừng mưa nhiệt đới, đây là khu bảo vệ có giá trị sử dụng về các mặt bảo tồn thiên nhiên, di tích văn hóa, nghiên cứu khoa học và tham quan du lịch. Nguồn tài nguyên sinh học nơi đây được nghiên cứu khá nhiều nhưng chủ yếu tập trung vào khu hệ động vật có xương sống (như các loài thú, chim, bò sát, lưỡng cư,...), một số nhóm côn trùng và thực vật khác (Nguyễn Thị Thu Anh và ctv., 2017), các nhóm động vật không xương sống trong đất trong đó có bọ đuôi bật (Collembola) lại chưa được nghiên cứu. Bài báo là những kết quả bước đầu nghiên cứu về đa dạng thành phần loài và đặc điểm phân bố của bọ đuôi bật, góp phần đánh giá đa dạng động vật không xương sống ở đất VQG, làm cơ sở cho việc nghiên cứu sự thay đổi chất lượng môi trường đất nhằm bảo vệ tài nguyên đất, đa dạng các nhóm động vật sống trong đất.

\section{VẠT LIỆU VÀ PHƯƠNG PHÁP NGHIẾN CÚU}

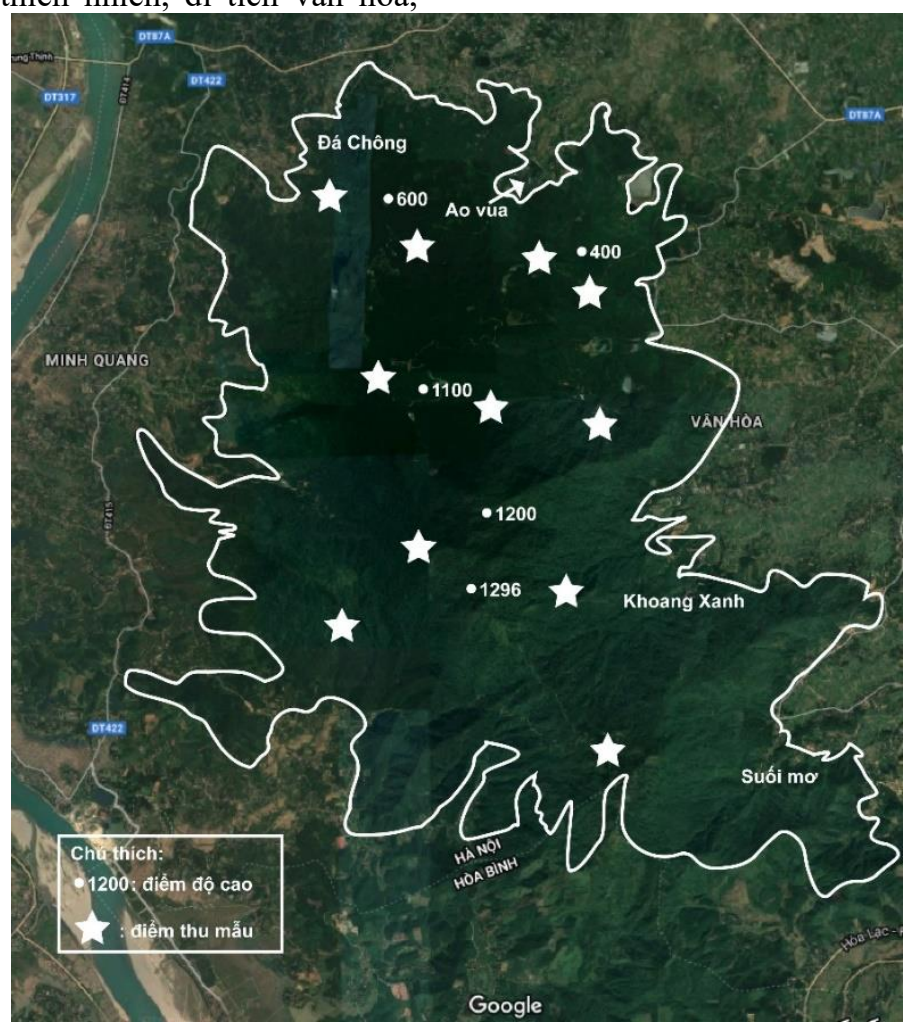

Hình 1. Sơ đồ điểm thu mẫu Collembola ở VQG Ba Vì

Mẫu Collembola được thu 4 đợt từ tháng 01 năm 2017 đến tháng 12 năm 2018 trên 3 kiểu sinh cảnh đại diện của hệ sinh thái rừng thuộc Vườn Quốc gia Ba Vì, khu vực Hà Nội bằng phương pháp thu mẫu đã được mô tả bởi Gormy and Grum (1993): (1) rừng thưa nhiệt đới: kiểu thảm thực vật này phân bố đều khắp ở vành đai độ cao 400m-700m xung quanh sườn núi $\mathrm{Ba} V \mathrm{~V}$, rừng phát triển trên loại đất Feralit vàng đỏ có mùn trên núi thấp, tầng đất mỏng có nơi tầng đất trung bình phát triển trên đá Pocphirit độ dốc cao bình quân 26-350, tầng mùn mỏng xói mòn mạnh tỷ lệ đá lẫn cao độ chua lớn; (2) rừng trồng thông (5 - 10 tuổi); (3) trảng cỏ nằm rải rác, dạng khảm, xen giữa các khoảng rừng thưa rộng. Trong mỗi sinh cảnh, thu 15 mẫu đất cho một đợt điều tra, 
tiến hành vào 2 mùa trong năm (mùa mưa: từ tháng 5 đến thang 10 và mùa khô: từ tháng 11 đến tháng 4) lấy ở lớp đất bề mặt từ $0-10 \mathrm{~cm}$ bằng dụng cụ chuyên dụng, cho vào túi nilon kèm theo nhãn (ghi đủ thông tin về địa điểm, ngày thu, sinh cảnh,...) và buộc chặt, chuyển về phòng thí nghiệm. Tổng số 180 mẫu đất đã được thu. Các mẫu vật được tách ra khỏi đất bằng phễu Berlese Tullgren trong thời gian 7 ngày đêm ở nhiệt độ phòng thí nghiệm và được định loại nhóm, loài bằng thiết bị hiện có và các tài liệu: Gisin (1960), Stach (1965), Yosii (1982a, 1982b, 1983), Deharveng et Bedos (1995, 1996, 2000). Nguyễn Trí Tiến (2017). Toàn bộ tiêu bản định loại và các mẫu vật được bảo quản tại phòng Sinh thái môi trường đất, Viện Sinh thái và Tài nguyên sinh vật, Viện Hàn lâm Khoa học và Công nghệ Việt Nam.

\section{KẾT QUẢ VÀ THẢO LUẬN}

\section{1. Đa dạng thành phần bọ đuôi bật ở Vườn Quốc gia Ba Vì}

Bảng 1 cho thấy có 83 loài Collembola thuộc 46 giống, 15 họ của 4 phân bộ phân bố trong 3 sinh cảnh đại diện của hệ sinh thái rừng VQG $\mathrm{Ba}$ Vì, trong số này, 71 loài (chiếm $85,54 \%$ ) đã xác định tên khoa học, 12 loài (chiếm 14,46\%) còn ở dạng chưa xác định tên loài. Các loài này gồm: Tullbergia $\mathrm{sp}_{.1}$, Protaphorura $\mathrm{sp}_{.1}$, Odontella $\mathrm{sp} .1_{1}$, Entomobrya sp.2, Homidia sp.3, Callyntrura sp.2, Arrhopalites sp.1, Sminthurinus sp.1, Deuterosminthurus sp.1, Sminthurus sp.1, Neosminthurus sp.1, Ptenothrix $\mathrm{sp}_{1}$, khi so sánh với các tài liệu hiện có - có thể xem đây là những loài mới được ghi nhận ở vườn quốc gia $\mathrm{Ba}$ Vì và sẽ được mô tả trong thời gian tới.

Bảng 1. Danh sách các loài Collembola ở vườn quốc gia Ba Vì

\begin{tabular}{|c|c|c|c|c|}
\hline STT & Thành phần loài & Rừng tự nhiên & Rù̀ng trồng & Trảng cỏ \\
\hline & PHÂN BỘ ENTOMOBRYOMORPHA. & & & \\
\hline & BORNER, 1913 & & & \\
\hline I & Họ Cyphoderidae Borner, 1913 & & & \\
\hline 1 & Cyphoderus javanus Borner, 1906 & + & + & + \\
\hline II & Họ Entomobryidae Schott,1891 & & & \\
\hline 2 & Dicranocentrus indicus Bonet, 1930 & + & + & + \\
\hline 3 & Entomobrya lanuginosa (Nicolet, 1842) & + & + & + \\
\hline 4 & Entomobrya muscorum (Nicolet, 1841) & & & + \\
\hline 5 & Entomobrya sp.2 & + & & + \\
\hline 6 & Homidia glassa Nguyen, 2001 & + & + & \\
\hline 7 & Homidia sauteri f. sinensis Denis, 1929 & + & + & \\
\hline 8 & Homidia socia Denis, 1929 & + & + & \\
\hline 9 & Homidia subcingula Denis, 1948 & + & + & \\
\hline 10 & Homidia $\mathrm{sp}_{.3}$ & + & & \\
\hline 11 & Lepidocyrtus (L.) cyaneus Tullberg, 1871 & + & + & \\
\hline 12 & Lepidocyrtus (L.) lanuginosus (Gmelin, 1788) & + & + & \\
\hline 13 & Lepidocyrtus (L.) simsim Yosii, 1982 & + & & + \\
\hline 14 & Lepidocyrtus (Acr.) heterolepis Yosii, 1959 & & + & \\
\hline 15 & Lepidocyrtus (Acr.) segamanus Yosii, 1982 & + & + & \\
\hline 16 & Lepidocyrtus (Acr.) transiens Yosii, 1982 & + & & \\
\hline 17 & Lepidocyrtus (Asc.) aseanus Yosii, 1982 & + & + & \\
\hline 18 & Lepidocyrtus (Asc.) cinctus Schaffer, 1898 & + & + & \\
\hline 19 & Lepidocyrtus (Asc.) concolourus Nguyen, 2001 & + & & + \\
\hline 20 & Lepidocyrtus (Asc.) dahlii Schaffer, 1898 & + & + & + \\
\hline 21 & Lepidocyrtus (Asc.) filamentsus Yosii, 1982 & & + & \\
\hline 22 & Lepidocyrtus (Asc.) sepilokensis Yosii, 1982 & & & + \\
\hline 23 & Pseudosinella alba (Packard, 1873) & + & + & \\
\hline 24 & Pseudosinella fujiokai Yosii, 1964 & + & & \\
\hline 25 & Pseudosinella immaculata (Lie-Petterson, 1896) & + & + & + \\
\hline 26 & Pseudosinella octopunctata Borner, 1901 & + & + & + \\
\hline 27 & Rambutsinella honchongensis Deharveng \& Bedos, & & & \\
\hline & 1996 & + & + & \\
\hline 28 & Seira camgiangensis Nguyen, 2001 & + & & \\
\hline 29 & Sinella coeca (Schott, 1896) & + & + & + \\
\hline
\end{tabular}




\begin{tabular}{|c|c|c|c|c|}
\hline STT & Thành phần loài & Rù̀ng tự nhiên & Rừng trồng & Trảng cỏ \\
\hline 30 & Sinella pseudomonoculata Nguyen, 1995 & + & + & + \\
\hline 31 & Willowsia alba Nguyen, 2005 & & + & + \\
\hline 32 & Willowsia bartkei Stach, 1965 & + & + & \\
\hline III & Họ Isotomidae Borner, 1913 & & & \\
\hline 33 & Cryptopygus thermophilus (Axelson, 1900) & & + & + \\
\hline 34 & Folsomides exiguus Folsom, 1932 & + & + & + \\
\hline 35 & Folsomides parvulus Stach, 1922 & + & & \\
\hline 36 & Folsomina onychiurina Denis, 1931 & + & + & + \\
\hline 37 & Isotomiella minor (Schaffer, 1896) & + & + & + \\
\hline 38 & Isotomodes pseudoproductus Stach, 1965 & + & + & + \\
\hline 39 & Isotomurus palustris (Muller, 1776) & + & + & + \\
\hline 40 & Isotomurus punctiferus Yosii, 1963 & + & + & + \\
\hline 41 & Proisotoma submuscicola Nguyen, 1995 & + & + & + \\
\hline IV & Họ Paronellidae Borner, 1906 & & & \\
\hline 42 & Callyntrura tamparuliana (Yosii, 1981) & + & + & \\
\hline 43 & Callyntrura sp.2 & + & + & \\
\hline 44 & Dicranocentroides clitellatus Yosii, 1982 & + & + & \\
\hline 45 & Lepidonella annulicornis (Oudemans, 1889) & + & & \\
\hline 46 & Salina celebensis (Schaffer, 1898) & + & + & + \\
\hline & $\begin{array}{l}\text { PHÂN BỘ NEELIPLEONA MOEN ET ELLIS, } \\
1984\end{array}$ & & & \\
\hline IV & Họ Neelidae Folsom, 1896 & & & \\
\hline 47 & Megalothorax minimus Willem, 1900 & + & + & + \\
\hline & PHÂN BỘ PODUROMORPHA BORNER, 1913 & & & \\
\hline $\mathbf{V}$ & Họ Hypogastruridae Borner, 1913 & & & \\
\hline 48 & Aherontiellina sabina Bonet, 1945 & + & + & \\
\hline 49 & Ceratophysella denticulata (Bagnall, 1941) & + & & \\
\hline 50 & Ceratophysella succinea Gisin, 1949 & + & & + \\
\hline 51 & Xenylla humicola (Fabricius, 1780) & + & + & \\
\hline VI & Họ Neanuridae Cassagnau, 1955 & & & \\
\hline 52 & Brachystomella parvula (Schaffer, 1896) & + & & + \\
\hline 53 & Friesea sublimis MacNamara, 1921 & + & & + \\
\hline 54 & Pseudachorutella asigillata (Borner, 1901) & + & & + \\
\hline 55 & Pseudachorutes dubius Krausbauer, 1898 & & + & \\
\hline 56 & Pseudachorutes subcrassus Tullberg, 1871 & + & & + \\
\hline 57 & Vitronura giselae (Gisin, 1950) & + & + & + \\
\hline 58 & Vitronura luzonica Yosii, 1976 & + & + & + \\
\hline 59 & Vietnura caerulea Deharveng \& Bedos, 2000 & & + & \\
\hline VII & Họ Odontellidae Stach, 1949 & & & \\
\hline 60 & Odontella $\mathrm{sp}_{.1}$ & + & & \\
\hline VIII & Họ Onychiuridae Borner, 1903 & & & \\
\hline 61 & Onychiurus ambulans (Linnaeus, 1758) & & + & \\
\hline 62 & Onychiurus saphianus Nguyen, 2001 & + & & \\
\hline 63 & Protaphorura tamdaona Nguyen, 1995 & + & & + \\
\hline 64 & Protaphorura sp.1 & + & & + \\
\hline \multirow[t]{2}{*}{65} & Tullbergia $\mathrm{sp}_{.1}$ & & + & \\
\hline & PHÂN BỘ SYMPHYPLEONA BORNER, 1901 & & & \\
\hline IX & Ho Arhopalitidae Stach, 1956 & & & \\
\hline 66 & Arrhopalites $\mathrm{sp} .1$ & + & & \\
\hline 67 & Collophora mysticiosa Yosii, 1966 & + & & \\
\hline $\mathbf{X}$ & Họ Bourletiellidae Banks, 1899 & & & \\
\hline 68 & Deuterosminthurus pallipes (Bourlet, 1843) & + & + & + \\
\hline 69 & Deuterosminthurus $\mathrm{sp}_{.1}$ & + & + & + \\
\hline
\end{tabular}




\begin{tabular}{|c|c|c|c|c|}
\hline STT & Thành phần loài & Rừng tự nhiên & Rừng trồng & Trảng cỏ \\
\hline XI & Họ Dicyrtomidae Borner, 1903 & & & \\
\hline 70 & Calvatomina antena (Nguyen, 1995) & + & + & + \\
\hline 71 & Calvatomina tuberculata (Nguyen, 2001) & + & + & + \\
\hline 72 & Ptenothrix $\mathrm{sp}_{.1}$ & + & & \\
\hline XIII & Họ Katiannidae Borner, 1913 sensu Stach, 1956 & & & \\
\hline 73 & Sminthurinus victorius Nguyen, 2001 & + & + & \\
\hline 74 & Sminthurinus sp.1 & + & + & \\
\hline XIV & Họ Sminthuridae Borner, 1913 & & & \\
\hline 75 & Sphyrotheca boneti (Denis, 1948) & + & & + \\
\hline 76 & Sphyrotheca macrochaeta Nguyen, 1995 & + & + & \\
\hline 77 & Sphyrotheca nepalica Yosii, 1966 & + & & \\
\hline 78 & Sminthurus sp.1 & & & + \\
\hline 79 & Neosminthurus $\mathrm{sp} .1$ & & & + \\
\hline XV & Họ Sminthurididae Borner, 1906 & & & \\
\hline 80 & Sminthurides aquaticus (Bourlet, 1842) & + & + & + \\
\hline 81 & Sminthurides bothrium Nguyen, 2001 & + & + & + \\
\hline 82 & Sphaeridia pumilis (Krausbauer, 1898) & + & + & + \\
\hline 83 & Sphaeridia zaheri Yosii, 1966 & + & + & + \\
\hline
\end{tabular}

Chú thích: +: ghi nhận loài

Trong 4 phân bộ, phân bộ Neelipleona chỉ có duy nhất 1 họ, 1 giống, 1 loài. Ba phân bộ còn lại có từ 4 - 6 họ/phân bộ. Phân bộ Symphypleona có số họ nhiều hơn cả (6 họ, chiếm $40 \%$ tổng số họ). Ở mức độ giống và loài, phân bộ Entomobryomorpha lại có tỷ lệ giống, loài chiếm vị trí cao nhất $(45,65 \%$ tổng số giống, 55,41\% tổng số loài) (Bảng 2).

Bảng 2. Số lượng giống, loài trong các họ, bộ Collembola ở VQG Ba Vì

\begin{tabular}{clrrrr}
\hline TT & Phân bộ và Họ & Số Giống & Số Loài & Tỷ lệ \%o so với & \\
\cline { 5 - 6 } & & 21 & 46 & 55,41 & Giống \\
\hline I & ENTOMOBRYOMORPHA & 1 & 1 & 1,21 & 45,65 \\
\hline 1 & Cyphoderidae & 9 & 31 & 37,35 & 19,17 \\
2 & Entomobryidae & 7 & 9 & 10,84 & 15,23 \\
3 & Isotomidae & 4 & 5 & 6,02 & 8,70 \\
4 & Paronellidae & 1 & 1 & 1,21 & 2,18 \\
\hline II & NEELIPLEONA & 1 & 1 & 1,21 & 2,17 \\
\hline 5 & Neelidae & 13 & 18 & 21,69 & 28,26 \\
\hline III & PODUROMORPHA & 3 & 4 & 4,82 & 6,52 \\
\hline 6 & Hypogastruridae & 6 & 8 & 9,64 & 13,04 \\
7 & Neanuridae & 3 & 5 & 6,02 & 6,52 \\
8 & Onychiuridae & 1 & 1 & 1,21 & 2,17 \\
9 & Odontellidae & 11 & 18 & 21,69 & 23,91 \\
\hline IV & SYMPHYPLEONA & 2 & 2 & 2,41 & 4,35 \\
\hline 10 & Arrhopalitidae & 1 & 2 & 2,41 & 2,17 \\
11 & Bourletiellidae & 2 & 3 & 3,61 & 4,35 \\
12 & Dicyrtomidae & 1 & 2 & 2,41 & 2,17 \\
13 & Katiannidae & 3 & 5 & 6,02 & 6,52 \\
14 & Sminthuridae & 2 & 4 & 4,82 & 4,35 \\
\hline 15 & Sminthurididae & 46 & 83 & 100 & 100 \\
\hline
\end{tabular}

Trong các họ ghi nhận, ba họ có số giống hiện diện nhiều nhất là: Họ Entomobryidae, Neanuridae, Isotomidae, (số lượng giống: 9, 7, 6 tương ứng, chiếm 47,83\% tổng số giống). Các họ còn lại, chỉ có từ $1-4$ giống / 1 họ. Trong đó, có 5 họ chỉ có 1 giống. Ở mức độ loài, số loài cũng tập trung chủ yếu ở 3 họ có số giống nhiều nhất (với 48 loài, chiếm $57,83 \%$ tổng số loài). Tính trung bình, 1 họ có 3,07 
giống và 5,53 loài. Mỗi giống có 1,8 loài. Như vậy, độ đa dạng của Collembola ở VQG Ba Vì khá cao ở mức độ giống và loài. So với một số $\mathrm{VQG}$, khu hệ Collembola VQG Ba Vì có mức độ đa dạng tương đương VQG Xuân Sơn (Nguyễn Trí Tiến và ctv, 2007b), nhưng lại cao hơn so với VQG Cát Bà và VQG Hoàng Liên về số lượng bậc taxon (loài, giống, họ) (Nguyễn Trí Tiến và ctv., 2007a; 2008; 2011).

\section{2. Đa dạng các nhóm phân loại Collembola}

Bọ đuôi bật hình thành một quần xã gồm nhiều loài, phản ánh tính khảm của quần xã thực vật trên mặt đất. Trong quần xã Collembola tồn tại những nhóm khác nhau về hình thái, về đặc tính dinh dưỡng, về nơi sống.... Chúng phát triển trong trạng thái cân bằng bên trong quần xã.

Khi phân tích các dẫn liệu, các nhóm sau thường được dùng để đánh giá mức độ cân bằng trong quần xã Collembola, đó là: Poduromorpha, Isotomidae, Entomobryidae, Symphypleona và Collembola khác, bởi vì các nhóm này đóng vai trò như nhau trong quần xã Collembola và khi đó, tạo ra mức cân bằng trong chính quần xã này (Betsch et al., 1981). Thực nghiệm đã chỉ ra rằng một quần xã Collembola phát triển tối ưu trong môi trường tự nhiên khi có sự cân bằng của các nhóm này và sự đóng góp của các loài trong mỗi nhóm sẽ là cơ sở để phản ánh điều kiện môi trường sinh thái nơi sinh vật cư trú (Betsch et al., 1981).

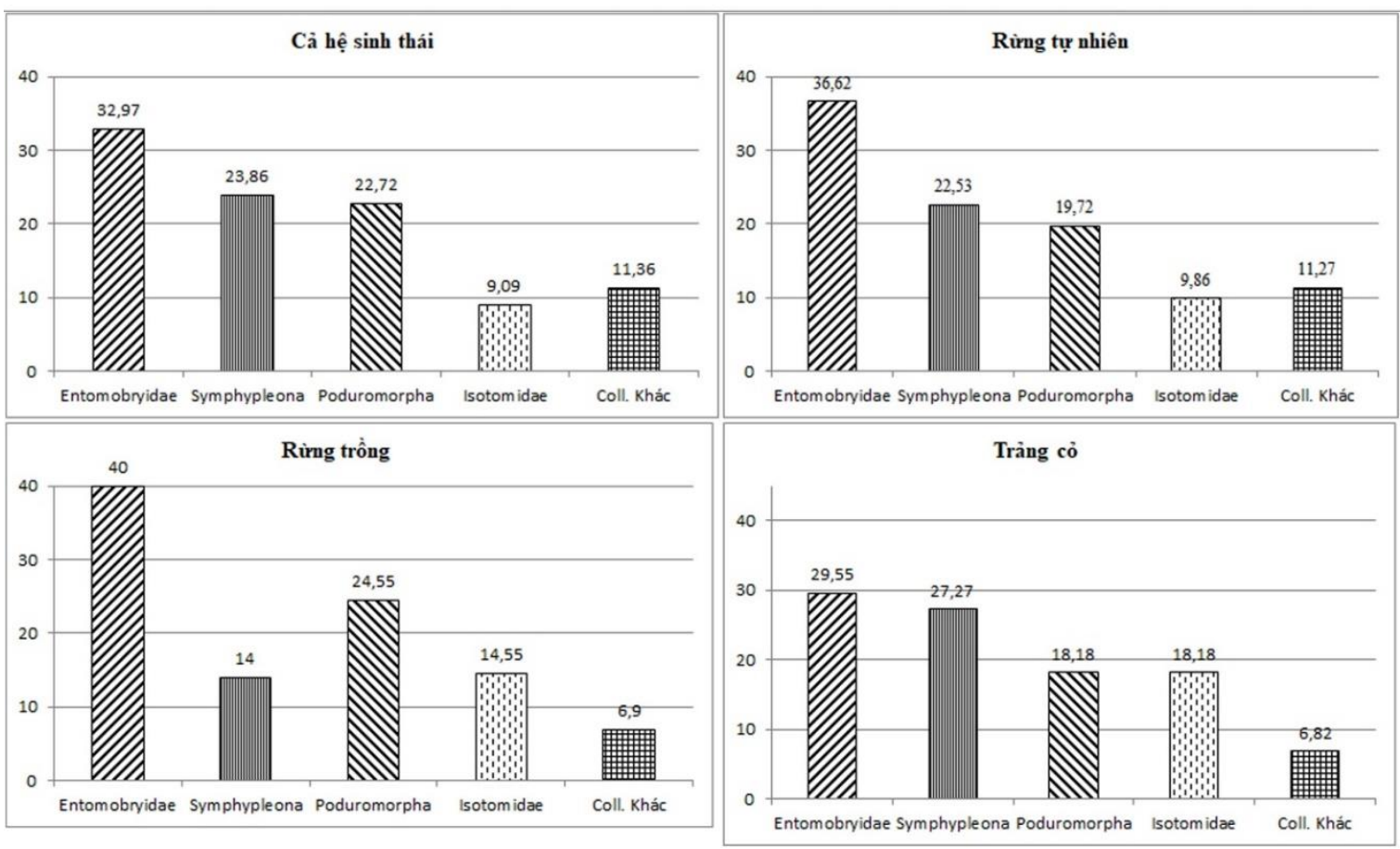

Hình 2. Tỷ lệ các nhóm trong quần xã bọ đuôi bật theo sinh cảnh ở VQG Ba Vì (Betsch et al., 1981)

Chú thích: Coll. khác: Collembola khác là các loài không thuộc Poduromorpha, Isotomidae, Entomobryidae và Symphypleona.

Phân tích Collembola trong các sinh cảnh nghiên cứu ở VQG Ba Vì theo 5 nhóm kể trên cho thấy tỷ lệ các nhóm thay đổi ở các sinh cảnh khác nhau, phụ thuộc vào điều kiện môi trường nơi sinh vật cư trú. Tính chung trong cả hệ sinh thái, nhóm Entomobryidae chiếm tỷ lệ cao nhất $(32,97 \%) ; 2$ nhóm Poduromorpha và Symphypleona chiếm tỷ lệ tương tự nhau $(22,72 \%$ và $23,86 \%$ tương ứng); 2 nhóm Isotomidae và Collembola khác cũng có tỷ lệ xấp xỉ nhau $(9,09 \%$ và $11,36 \%)$. Đối với 3 sinh cảnh nghiên cứu, tỷ lệ của nhóm Poduromorpha tăng lên và nhóm Symphypleona lại giảm đi ở sinh cảnh rừng trồng. Nhóm symphypleona đạt tỷ lệ cao hơn ở trảng cỏ, trong khi đó, nhóm Collembola khác có tỷ lệ cao nhất ở rừng tự nhiên. Tỷ lệ các nhóm phụ thuộc vào sự có mặt của các cư dân và điều kiện sinh thái cụ thể của sinh cảnh. Ở đây, tỷ lệ nhóm Collembola khác cao nhất đạt được ở rừng tự nhiên vì liên quan đến sự có mặt của các đại điện thuộc họ Paronellidae với $5 / 71$ loài (chiếm $7,04 \%$ số loài của sinh cảnh), mà hầu hết các đại diện của họ này chỉ cư trú và phát triển ở rừng tự nhiên với lớp thảm vụn hữu cơ dầy, 
ẩm ướt, ở những nơi ít ánh sáng do có tầng thực vật phủ là các cây thân gỗ che kín. Trong khi đó, trảng cỏ là nơi cư trú của nhiều loài thuộc giống Sminthurides, Sphyrotheca... ưa ánh sáng, thường ưa thích các sinh cảnh mở với lớp thảm là cây thân thảo.

\section{3. Đa dạng các nhóm dạng sống Collembola}

Dựa trên cơ sở bảng phân loại các nhóm dạng sống theo Stebaeva (1988) và Nguyễn Trí Tiến (1995), phân tích toàn bộ các mẫu vật Collembola thu được ở VQG Ba Vì, các loài đã gặp thuộc vào 3 nhóm dạng sống chính: nhóm sống trên bề mặt thảm và không gian (nhóm thảm); nhóm sống trong lớp thảm, bên trên mặt đất (nhóm thảm - đất) và nhóm sống ở các tầng nông, sâu của đất (nhóm đất). Các nhóm này chiếm các tỷ lệ số lượng khác nhau và thay đổi theo từng sinh cảnh, theo từng mùa.

Đối với cả hệ sinh thái rừng của VQG $\mathrm{Ba}$ Vì, nhóm thảm - đất và nhóm đất có tỷ lệ tương đương nhau, nhưng đối với từng sinh cảnh riêng, tỷ lệ các nhóm này thay đổi: nhóm thảm-đất giảm theo trật tự: rừng tự nhiên > rừng trồng > trảng cỏ, ngược lại, tỷ lệ của nhóm đất tăng lên từ rừng tự nhiên $>$ rừng trồng > trảng cỏ. Nhóm thảm có tỷ lệ thấp nhất ở trảng cỏ. Chiều hướng tăng, giảm tỷ lệ các nhóm này, rõ ràng tương ứng với điều kiện sinh thái cụ thể của sinh cảnh: lớp thảm vụn hữu cơ mỏng dần đến không có từ rừng tự nhiên qua rừng trồng đến trảng cỏ. Những đại diện sống trên và trong lớp thảm vụn vắng mặt dần, thay thế vào đó là sự gia tăng các loài sống ở các tầng nông sâu của đất.

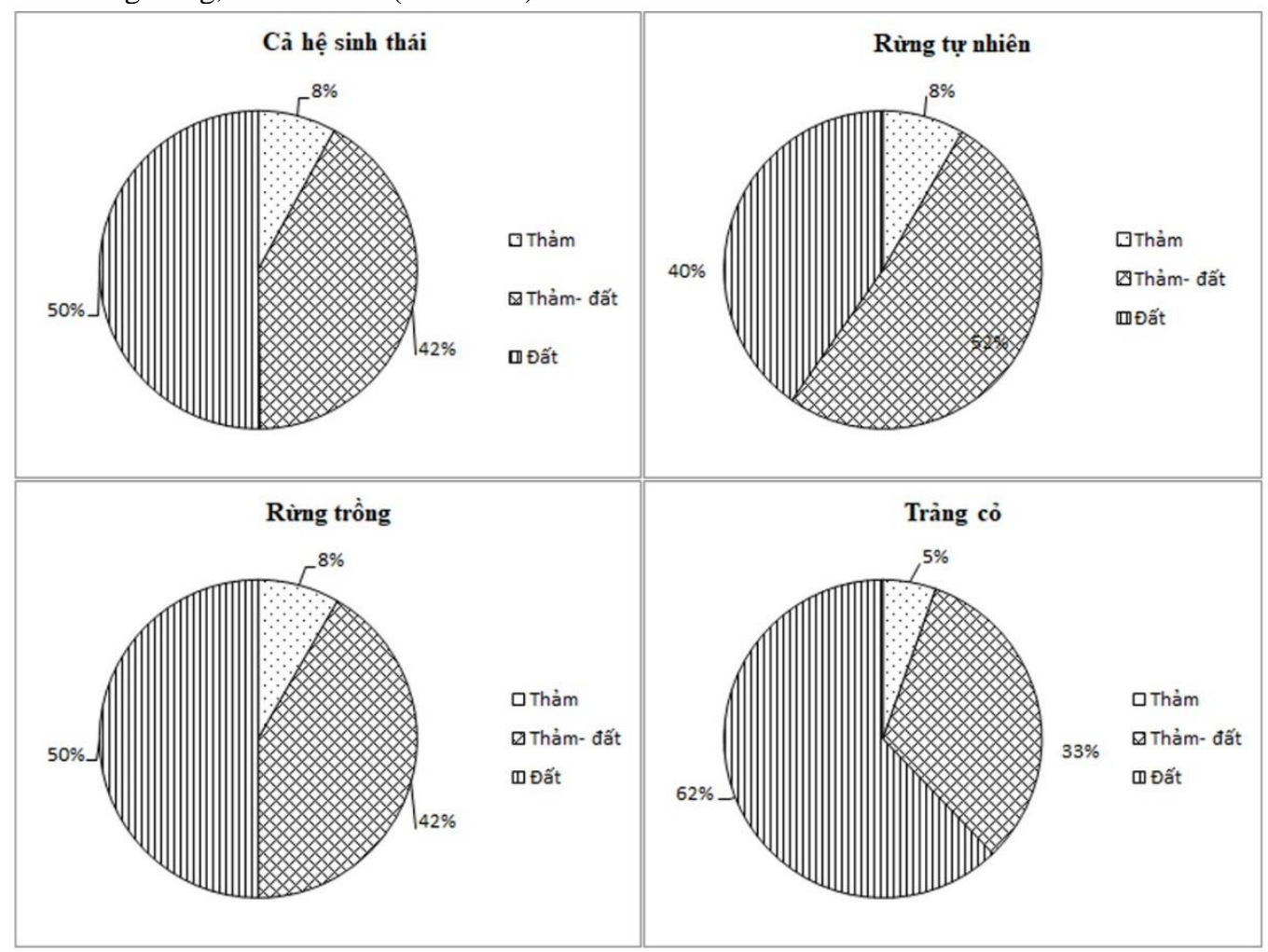

Hình 3. Tỷ lệ\% các nhóm dạng sống Collembola theo sinh cảnh ở VQG Ba Vì

\section{4. Đặc điểm phân bố của Collembola và sự thích nghi của Collembola với sinh cảnh sống ở VQG Ba Vì}

Trong số 83 loài ghi nhận ở VQG Ba Vì, có 12 loài (chiếm 14,46 \% tổng số loài) thuộc nhóm phân bố sinh thái rộng (là những loài có mặt trong cả 3 sinh cảnh và ở 5-6 lượt mùa thu mẫu), bao gồm: Folsomides exiguus, Proisotoma submuscicola, Isotomodes pseudoproductus (Isotomidae);
Entomobrya lanuginosa, Pseudosinella immaculata, Pseudosinella octopunctata, Dicranocentrus indicus (Entomobryidae); Cyphoderus javanus (Cyphoderus); Sminthurides aquaticus, Sphaeridia pumilis (Sminthurididae); Calvatomina antena và Calvatomina tuberculata (Dicyrtomidae) . Đây có thể xem là tập hợp những loài Collembola đại diện cho hệ sinh thái rừng VQG $\mathrm{Ba}$ Vì. Trong 12 loài này, có 4 loài: Cyphoderus javanus, Pseudosinella octopunctata, 
Dicranocentrus indicus, Calvatomina tuberculata sống trên, trong lớp thảm - trên mặt đất, Sminthurides aquaticus và Sphaeridia pumilis sống ở lớp đất bề mặt hay trong các khe kẽ có sẵn trong đất, 8 loài còn lại đều là những cư dân điển hình của nhóm sống trong các tầng nông, sâu của đất. Chúng có kích thước cơ thể nhỏ, thân không có sắc tố, khá bền vững với mọi tác động ngoại sinh và thích nghi trong nhiều điều kiện sống khác nhau: đất nông nghiệp, đất rừng và đất đô thị.

Một số loài chỉ mới gặp ở một sinh cảnh nghiên cứu, hoặc rừng tự nhiên, hoặc rừng trồng, hoặc trảng cỏ, cụ thể:

- Rừng tự nhiên với 13 loài: Onychiurus saphianus, Odontella sp.1, Ceratophysella denticulata, Folsomides parvulus, Homidia $\mathrm{sp}_{3}$, Pseudosinella fujiokai, Lepidocyrtus (Acr.) transiens, Seira camgiangensis, Lepidonella annucornis, Arrhopalites sp. 1 , Collophora mysticiosa, Sphyrotheca nepalica, Ptenothrix sp.1,

- Rừng trồng với 6 loài: Tullbergia $\mathrm{sp}_{.1}$, Onychiurus ambulans, Pseudachorutes dubius, Vitronura caerulea, Lepidocyrtus (Acr.) heterolepis, Lepidocyrtus (Asc.) filamentosus.

- Trảng cỏ cũng với 4 loài: Entomobrya muscorum, Lepidocyrtus (Asc. ) sepilokensis, Sminthurus sp. ${ }_{1}$, Neosminthurus $\mathrm{sp}_{\cdot 1}$.

Xét về số lượng loài riêng của từng sinh cảnh cho thấy tính đa dạng của rừng tự nhiên vượt trội so với rừng trồng và trảng cỏ. Khá nhiều loài chỉ ghi nhận được ở rừng tự nhiên mà không có mặt ở rừng trồng và trảng cỏ. Sinh cảnh rừng (rừng trồng hay rừng tự nhiên) đa dạng về số loài hơn so với sinh cảnh còn lại và sự khác nhau về thành phần loài của quần xã bọ nhảy (Collemboala) ở sinh cảnh rừng với sinh cảnh còn lại đã phản ánh các điều kiện môi trường của sinh cảnh. Nếu theo chiều hướng tác động nhân tác (rừng tự nhiên $\rightarrow$ rừng trồng $\rightarrow$ trảng cỏ cây bụi), thì có thể thấy sự có mặt của những loài có nguồn gốc từ rừng không được tìm thấy ở các quần xã Collembola ở sinh cảnh có tác động của các hoạt động nhân tác. Như vậy, sự thay đổi số lượng loài ghi nhận được ở các sinh cảnh nghiên cứu có liên quan đến sự thay đổi thảm thực vật và mức độ tác động của con người. Điều này cũng đã được ghi nhận ở các nghiên cứu trước đây của Nguyễn Trí Tiển (2001), Nguyễn Trí Tiến và ctv. (2008), Nguyễn Thị Thu Anh \& Nguyễn Trí Tiến (2005), Nguyễn Thị Thu Anh và ctv. (2013), Dương Thị Thanh và ctv. (2010).
Xét về số lượng cá thể riêng từng loài, cũng như sự có mặt của chúng ở các kiểu sinh cảnh khác thuộc các địa điểm ngoài $\mathrm{HST}$ rừng $\mathrm{Ba}$ Vì, có thể nhận định chỉ có một vài loài Collembola có tên sau đây là có thể xem đặc trưng cho kiểu sinh cảnh mà chúng cư trú: Đặc trưng cho sinh cảnh rừng tự nhiên: Lepidonella annucornis, Callyntrura sp.2, Dicranocentroides clitellatus, Arrhopalites sp. 1 , Ptenothrix $\mathrm{sp}_{.1}$. Đặc trưng cho rừng trồng chỉ có 1 loài: Pseudachorutes dubius. Đặc trưng cho trảng cỏ có 2 loài: Sminthurus sp. ${ }_{1}$, Neosminthurus sp. ${ }_{1}$. Các loài còn lại khác, số lượng cá thể rất ít, hơn nữa, cũng chỉ thu được mẫu trong một hoặc hai lần thu nên hiện tại, chúng chỉ xem là những loài bắt gặp ngẫu nhiên trong đợt điều tra, không phải là loài đặc trưng cho sinh cảnh nơi chúng cư trú.

\section{KẾT LUẬN}

Cho đến nay, đã ghi nhận được được 83 loài Collembola (bao gồm cả các dạng sp.) thuộc 46 giống, 15 họ phân bố trong 3 sinh cảnh nghiên cứu của VQG Ba Vì. Mức độ đa dạng của Collembola ở VQG Ba Vì khá cao ở mức độ giống và loài. Tập hợp các nhóm phân loại và nhóm sinh thái của Collembola thay đổi ở các sinh cảnh khác nhau và phụ thuộc vào điêu kiện sinh thái cụ thể của từng sinh cảnh. Bước đầu đã xác định các loài đặc trưng: cho sinh cảnh rừng tự nhiên Lepidonella annucornis, Callyntrura sp.2, Dicranocentroides clitellatus, Arrhopalites sp.1, Ptenothrix sp.1; cho rừng trồng: Pseudachorutes dubius; đặc trưng cho trảng cỏ: Sminthurus sp.1, Neosminthurus sp.1. Có thể xem 12 loài sau là tập hợp những loài Collembola đại diện cho hệ sinh thái rừng VQG Ba Vì: Folsomides exiguus, Proisotoma submuscicola, Isotomodes pseudoproductus (Isotomidae); Entomobrya lanuginosa, Pseudosinella immaculata, Pseudosinella octopunctata, Dicranocentrus indicus (Entomobryidae); Cyphoderus javanus (Cyphoderus); Sminthurides aquaticus, Sphaeridia pumilis (Sminthurididae); Calvatomina antena và Calvatomina tuberculata (Dicyrtomidae).

Sự phân bố về số lượng và thành phần loài Collembola theo từng sinh cảnh cho thấy tính đa dạng của rừng tự nhiên vượt trội so với rừng trồng và trảng cỏ.

Mức độ thay đổi về đa dạng thành phần loài và phân bố của Collembola ở các sinh cảnh nghiên cứu có liên quan đến sự thay đổi thảm thực vật và mức độ tác động của con người. Cần thiết phải tiến hành nghiên cứu mở rộng thêm về không gian, thời gian, 
độ cao,... để có những dẫn liệu đầy đủ hơn của nhóm động vật chân khớp bé.

\section{LỜI CẢM ƠN}

Nghiên cứu này được thực hiện với sự hỗ trợ kinh phí từ Đề tài khoa học công nghệ cấp cơ sở, mã số IEBR.DT.01/G2-18.

\section{TÀI LIỆU THAM KHẢO}

Betsch, J.M., Betsch-Pinot, M.C. \& Mikhalevich, Y. (1981). Evolution des peulements de microarthropodes du soil en fonction des traitements subic par une foret dense humid en Guyane francaice. Acta Ecologia Ecol. Gener., 2(3), 245-263.

Deharveng, L. \& Bedos, A. (1995). Lepidonella lecongkieti n. Sp., premier Collembole cavernicole du Vietnam (Collembola, Paronellidae). Bulletin de la Societe Entomologique de France, 100(1), 21-24.

Deharveng, L. \& Bedos, A. (1996). Rambutsinella, a new genus of Entomobryidae (Insecta: Collembola) from Southeast Asia. The Raffles Bulletin of Zoology, 44(1), 279-285.

Deharveng, L. \& Bedos, A. (2000). Vietnura caerulea, new genus, new species from Vietnam: First record of the Palaearctic the tribe Neanurini in tropical Asia (Collembola: Neanuridae). The Raffles Bulletin of Zoology, 48(2), 209-214.

Dương Thị Thanh, Nguyễn Trí Tiến \& Nguyễn Thị Thu Anh. (2010). Khu hệ Collembola (Insecta) ở một số đô thị vùng đồng bằng sông Hồng. Tạp chí Công nghệ sinh học 8(3A), 1021-1030.

Gisin, H. (1960). Collembolen fauna Europas. Museum D’Histoire Naturelle, Geneve, 1-300.

Gormy C. \& Grum L. (1993). Methods in Soil Zoology. PWN- Polish Scientife publisher, Warszawa, 518-620.

Nguyễn Thị Thu Anh, Lê Quốc Doanh và Nguyễn Quang Tin. (2013). Quần xã Bọ đuôi bật (Collembola) ở đất trồng ngô xã Sơn Thịnh, huyện Văn Chấn, tỉnh Yên Bái. Trong: Tuyển tập các công trình nghiên cúu sinh thái và tài nguyên sinh vật (trang 1284-1291). Nxb Khoa học Kỹ thuật.

Nguyễn Thị Thu Anh, Nguyễn Thị Thắm, Đào Duy Trinh \& Dương Thị Thanh. (2017). Thành phần loài ve giáp (Acari: Oribatida) tại sinh cảnh rừng tự nhiên, rừng trồng và vùng phụ cận vườn quốc gia Ba Vì. Trong: Hội nghị khoa học toàn quốc lần thú 7 (trang 22-29). Nxb. Khoa học tự nhiên và Công nghệ.

Nguyễn Thị Thu Anh \& Nguyễn Trí Tiến. (2005a). Một số đặc điểm định lượng và các nhóm dạng sống, nhóm sinh thái của bọ nhảy (Insecta: Collembola) phân bố theo sinh cảnh trong hệ sinh thái đô thị ở vùng đồng bằng sông Hồng. Tạp chí Sinh hoc, 27(2), 89-92.

Nguyễn Thị Thu Anh \& Nguyễn Trí Tiến. (2005b). Thành phần loài của hai nhóm bọ nhảy (Collembola) và ve giáp (Oribatei) ở vùng đồi tỉnh Phú Thọ. Tạp chí Sinh hoc, 27(4A), 152-157.

Nguyễn Trí Tiến. (1995). Một số đặc điểm cấu trúc quần xã bọ nhảy (Collembola) ở các hệ sinh thái Bắc Việt Nam (Luận án Phó tiến sĩ khoa học sinh học). Viện Sinh thái và Tài nguyên sinh vật, Hà Nội.

Nguyễn Trí Tiến. (2001). Sáu loài Collembola mới thuộc họ Entomobryidae được phát hiện ở Việt Nam. Tap chí Sinh hoc, 23(1), 21-29.

Nguyễn Trí Tiến (2017). Động vật chí Việt Nam (Bộ Collembola), tập 30 .

Nguyễn Trí Tiến, Nguyễn Thị Định \& Nguyễn Thị Thu Anh. (2008). Đa dạng loài và phân bố của bọ nhảy (Insecta: Collembola) ở khu vực phía tây tỉnh Quảng Nam, Thừa Thiên Huế và Quảng trị. Trong: Hội nghị Côn trùng học toàn quốc là̀n thư 6 (trang 371-380). Nxb. Nông nghiệp, Hà Nội.

Nguyễn Trí Tiến, Thái Trần Bái \& Nguyễn Đức Tú. (2011). Khu hệ Collembola vườn quốc gia Hoàng Liên, Lào Cai. Trong: Hội nghị Côn trùng học Quốc gia lần thư 7 (trang 356-362). Nxb. Nông nghiệp, Hà Nội.

Nguyễn Trí Tiến, Nguyễn Thị Định, Nguyễn Đức Anh \& Nguyễn Văn Quảng. (2007a). Đa dạng sinh học, đặc điểm phân bố của bọ nhảy (Collembola) ở vườn quốc gia Cát Bà, Hải Phòng. Trong: Hội nghị khoa hoc Toàn quốc về Sinh thái và Tài nguyên sinh vật lần thứ 3 (trang 608-613). Nxb. Nông nghiệp, Hà Nội.

Nguyễn Trí Tiến, Nguyễn Văn Quảng \& Lê Thị Quyên. (2007b). Khu hệ Collembola vườn quốc gia Xuân Sơn.Trong: Hội nghị toàn quốc nhũng vấn đề NCCB trong KHSS (trang 195-198). Nxb Khoa học và Kỹ thuật, Hà Nội.

Stach, J. (1965). On some Collembola of North Vietnam. Acta. Zool. Cracoviensia, 10(4), 345-372.

Stebaeva, C.K. (1988). Hình thái Collembola. Trong: Định loại khu hệ Collembola Liên Xô. Nxb. Khoa học, Moskva, 33-35 (tiếng Nga).

Yosii, R. (1982a). Entomological Report from the Sabah Forest Research Centre. No. 5 Lepidocyrtid Collembola of Sabah. Japan International Cooperation Agency, p. 47.

Yosii, R. (1982b). Entomological Report from the Sabah Forest Research Centre. No. 6 Studied on the Collembolan Genus Callyntrura and Dicranocentorides. Japan International Cooperation Agency, p. 38.

Yosii, R. (1983). Entomological Report from the Sabah Forest Research Centre. No. 7 Studied on Paronellid Collembola of East Asia. Japan International Cooperation Agency, p. 28 